\title{
Guerra fiscal: a crise federativa e suas soluções legislativas e doutrinárias ${ }^{1}$
}

\author{
Rudolf Minikowski Ziegler ${ }^{2}$ \\ Sharon Cristine Ferreira de Souza ${ }^{3}$
}

\section{Resumo}

\begin{abstract}
Análise dos diversos problemas levantados pela doutrina a respeito da concessão unilateral de isenção de ICMS, uma das formas de benefício fiscal, em detrimento dos convênios interestaduais, causando assim a chamada guerra fiscal. Em que pese o bom papel desempenhado pelo STF no combate a essas práticas, somente nova legislação poderia resolver o problema. Destarte, diversas são as soluções levantadas em nível doutrinário e legislativo que poderiam desaguar na harmonização da Federação Brasileira e, bem assim, no desenvolvimento econômico do País.
\end{abstract}

Palavras-Chave: ICMS; Isenção; Convênios; Guerra fiscal; Projetos de leis.

\section{Introdução}

Embora doutrina e jurisprudência caminhem no sentido de revogar isenções unilateralmente concedidas por quaisquer dos Estados da Federação, mediante Ação Direita de Inconstitucionalidade (ADIn) impetrada no Supremo Tribunal Federal (STF), não é o melhor caminho discutir no Judiciário os problemas decorrentes da guerra fiscal entre os entes federados.

As grandes divergências atinentes às concessões indevidas de ICMS tornaram-se regra, fazendo-se necessária a busca de uma solução jurídica mostrando saídas mais eficazes, que possibilitem a obediência de princípios constitucionais e, por conseguinte, do atendimento aos interesses públicos.

Sendo assim, uma breve explicação a respeito do assunto, com o enfoque em algumas das maiores questões e algumas soluções trazidas pela doutrina e legislação.

1 Trabalho apresentado como requisito parcial de conclusão da disciplina de Direito Tributário do curso de Direito da Universidade Estadual de Londrina.

2 Acadêmico do 50 ano de direito da Universidade Estadual de Londrina.

3 Acadêmica do 50 ano de direito da Universidade Estadual de Londrina. 


\section{Isenção}

Definida como "limitação legal do âmbito de validade da norma jurídica tributária, que impede que o tributo nasça ou faz com que ele surja de modo mitigado" (CARRAZZA, 2003, p. 369), a isenção é matéria diretamente ligada à competência tributária, conquanto só está constitucionalmente autorizado a aumentar, diminuir ou eximir de pagamento do valor de determinado tributo, o ente competente para instituí-lo (CARRAZZA, 2003, p. 369).

Este preceito é claramente observado no art. 151, III, da Constituição Federal, no qual se veda à União conceder isenções de tributos de competência dos Estados, Distrito Federal e Municípios.

O ICMS, sendo imposto de alçada estadual, só pode ter certos componentes de sua norma jurídica tributária atenuados - de forma a limitar sua incidência - pelos Estados ou Distrito Federal, consoante os ditames do dispositivo no art. 155, § 2으, II, da Carta Magna.

Porém, mesmo tendo autorização constitucional para isentarem certas operações de circulação de mercadorias - como um dos inúmeros instrumentos de incentivo fiscal não podem os Estados ou o Distrito Federal concederem tal espécie de benefício de maneira autonômica, nem mesmo por meio de lei ordinária.

Cabe, então, à lei complementar regular o modo, trazer os mecanismos jurídicos e as limitações técnicas de como tais entes federados concederão ou revogarão as isenções (art. 155, § 2으, XII, g, da Constituição Federal). A partir deste entendimento, infere-se que a isenção deverá ser concedida por meio de convênios, ou seja, acordos, combinações, ajustes firmados entre as unidades federativas, e, ulteriormente, ratificados pelas assembléias legislativas mediante decreto legislativo.

As isenções de ICMS podem ser concedidas incondicional - unilaterais ou gratuitas, independendo de cumprimento de qualquer requisito especial por parte do beneficiário - ou condicionalmente - bilaterais ou onerosas, exigindo contraprestação adequada e pertinente, salvo, é claro, absurdos, feitos impossíveis ou que acarretem em maior gravame da carga tributária. Bastará ao beneficiário, pois, preencher, ou não, os requisitos numerados na norma isentiva (CARRAZZA, 2003, p. 376).

No tangente à revogação das isenções, há entendimento no sentido de que uma vez concedida isenção por prazo determinado e com base no preenchimento de certas 
condições, há direito adquirido, tornando-a irrevogável pelo Poder Público quando não verificado seu termo final, nem tampouco a inobservância das condições exigidas.

Se as isenções forem concedidas mediante decreto legislativo, só podem ser revogadas por outro decreto legislativo, e não por meio de lei ordinária. Sustenta-se que a revogação da isenção de ICMS deve obedecer ao princípio da anterioridade, de maneira que os decretos legislativos aptos a tributar novamente só poderão incidir no exercício financeiro seguinte.

Situação diversa ocorre quando a isenção de ICMS é concedida por lei complementar. Não há, neste caso, revogação das leis estaduais e distritais que com ela conflitem, mas apenas a paralisia de sua eficácia. Destarte, revogada por outra lei complementar, a eficácia destas leis se restabelece plenamente - readquirem eficácia jurídica - e de imediato, pois o princípio da anterioridade, o qual as alcançou no passado quando entraram em vigor - a elas não mais se aplica (CARRAZZA, 2003, p. 377-378).

Em realidade, é de costume observar a Administração Pública valendo-se de expressões como "alíquota $0 \%$ ", diferimento, imunidade etc., para tentar demonstrar não existir a figura da isenção no caso em questão e, assim, poder majorar a alíquota sem respeito à anterioridade.

Após breve explanação sobre as isenções, faz-se mister discorrer sobre os convênios, a fim de tornar possível a compreensão ampla acerca do problema da guerra fiscal e suas possíveis soluções levantadas em âmbito legal.

\section{Convênios}

No ICMS, nem Estados-Membros, nem o Distrito Federal podem conceder isenções - ou qualquer outro tipo de incentivos e benefícios fiscais - unilateralmente, mesmo embasadas em lei.

O modo constitucionalmente correto de se conceder isenções é por intermédio de firmação de convênios (art. 155, § 2으, XII, g, da Constituição), celebrados no Conselho Nacional de Política Fazendária (CONFAZ), órgão onde têm assento representantes de cada Estado e do Distrito Federal - indicados pelos Governadores. Tenha-se em mente, portanto, que convênio não é lei e o CONFAZ não é órgão legislativo, assim, suas deliberações não são eficazes sem aceite do Poder Legislativo - por representantes do povo - de cada Estado e do 
Distrito Federal. Esse aval é externado mediante decreto legislativo ratificador do convênio interestadual.

A importância do convênio reside em seu papel consensual, o qual deflagra o processo legislativo, encerrado somente com aludido decreto, que concede, efetivamente, a isenção. Tem ele o caráter de pressuposto para a concessão de isenções. Apregoa Geraldo Ataliba (apud CARRAZZA, 2003, p. 373-374):

[...] o convênio não dá nem tira direito a nenhuma Fazenda e a nenhum contribuinte. Não cria direito de natureza tributária nem em benefício, nem em detrimento de ninguém. É mero pressuposto de exercício eficaz da competência isentadora dos legisladores ordinários estaduais.

Todavia, sub-repticiamente, os convênios vêm sendo ratificados por decreto do Governador com base no art. 4ㅇ da Lei Complementar n. 24/75 - que, neste ponto específico, não foi recepcionado pela sistemática da Constituição Federal de 1988, a qual imprime especial importância ao princípio da legalidade. O ideal instrumento introdutório de normas no ordenamento jurídico a ser utilizado, nesta situação, é, sem dúvida, o decreto legislativo, pois é lei em sentido amplo e, destarte, possibilita a obediência ao supra-referido princípio constitucional.

A fim de evitar a "guerra fiscal", salienta-se ser imprescindível a todos os Estados e o Distrito Federal ratificarem, por unanimidade, o convênio interestadual para dar eficácia a qualquer tipo de isenção do ICMS.

\section{Guerra fiscal}

Consoante anterior menção, os incentivos ou benefícios fiscais são mecanismos, instituídos pelo Ente Público, mediante os quais há uma desoneração de determinados tributos, com o escopo de fazer o contribuinte adotar comportamentos de modo a proporcionar a emulação da economia por meio de atividades e investimentos neste setor, segundo certos interesses públicos (MELO, 2004, p. 268; SILVA, 2003, p. 225).

As isenções são espécie de incentivo fiscal - bem como alíquotas reduzidas, suspensão de impostos, diferimento, manutenção de créditos, créditos especiais, dentre 
outros - que devem ser concedidas mediante convênios, nunca de modo unilateral, como atualmente ocorre, ocasionando problemas de guerra fiscal entre os entes federados.

Acerca deste tema pode-se discorrer sobre uma série de problemas e celeumas apontados pela doutrina e jurisprudência, envolvendo, principalmente, o princípio federativo.

O Texto Maior preceitua o seguinte fundamento em seu art. 10: “A República Federativa do Brasil, formada pela união indissolúvel dos Estados e Municípios e do Distrito Federal [...]". Verifica-se a estipulação da forma de Estado trazida pela expressão 'federativa' no caput do dispositivo acima transcrito, corroborada, ainda, pelo art. 25 da mesma Constituição, em cujo conteúdo se deposita a autorização para os Estados organizarem-se e regerem-se pelas Constituições e leis que adotarem.

O princípio federativo é cláusula pétrea e erige os Estados como entidades autônomas, podendo deliberar, com aval constitucional, sobre a ordem jurídica tributária e assuntos interessantes a esta relacionados, condizentes, é claro, com as matérias que the competem (CARRAZZA, 2003, p. 379-381).

Segundo o entendimento de muitos Estados, ${ }^{4}$ a insistência na manutenção das concessões de isenção de ICMS é embasada nos ditames do princípio em tela, pois sua obediência se traduz numa autorização de dispor sobre seus interesses, conforme sua autonomia político-jurídica, trazida pela competência tributária.

Ocorre, ao contrário do que se imagina, um enfraquecimento do federalismo brasileiro, conquanto se privilegia tradicionais oligarquias políticas regionais em detrimento

\footnotetext{
4 "Nos últimos anos, a resistência dos governadores do Centro-Oeste em acabar com os incentivos fiscais foi um dos principais empecilhos para a aprovação do texto [da reforma tributária em trâmite desde 2003] [...]" (GOBETTI, Estado..., 6 nov. 2006, Caderno A, p. 6).

"A receita de ICMS de Estados menos desenvolvidos das regiões Norte, Nordeste e Centro-Oeste cresceu $87,2 \%$ nos últimos 11 anos. O número representa quase o dobro do valor registrado nas regiões Sul e Sudeste (42,1\%). Os dados são do Conselho Nacional de Política Fazendária (Confaz) e explicam a resistência em acabar com a guerra fiscal.

Foi por meio de incentivos fiscais [...] que as regiões menos desenvolvidas conseguiram aumentar sua arrecadação no período posterior ao Plano Real.

Em Mato Grosso, por exemplo, o governo atrai empresas com isenção de ICMS, mas arrecada cada vez mais impostos com a venda de produtos primários - o que explica a oposição do governador Blairo Maggi à proposta do governo federal de reduzir o imposto sobre os produtos da cesta básica.

[...]

Em 1995, as regiões mais pobres acumulavam 23,5\% da receita anual de ICMS; hoje já ficam com 28,8\% uma diferença de $\mathrm{R} \$ \mathrm{~g}$ bilhões anuais. [...]

A maior parte desse ganho de receita foi extraído de São Paulo. Há 11 anos o Estado acumulava 37,6\% da arrecadação do ICMS, e hoje, 32,9\%" (GOBETTI, Unidades..., 6 nov. 2006, Caderno A, p. 6).
} 
de um amplo desenvolvimento econômico em nível nacional, que seria corretamente elaborado com uma lei nacional reguladora da matéria, possibilitando o equilíbrio federativo, o cotejamento, pelos entes federados, de diversos princípios referentes ao assunto, verificação de desigualdades econômicas em âmbito geral e uniformização no tratamento da concessão deste benefício fiscal (COSTA, 2002, p. 85-98).

Argumenta-se, num outro sentido, que a concessão unilateral de isenção do ICMS ou outro instrumento de benefício fiscal ou financeiro, por meio de leis, decretos e atos administrativos, fere as regras estabelecidas pela Lei Complementar n. 24, de 7 de janeiro de 1975 - que disciplina a necessidade de convênio -, recepcionada pelo ordenamento jurídico vigente como forma de evitar a guerra fiscal.

A entidade Pensamento Nacional das Bases Empresariais (PNBE) consultou o Conselho Administrativo de Defesa Econômica (Cade) a respeito dos aspectos concorrenciais envolvendo as unidades federativas na ambiência da guerra fiscal, obtendo como resposta que tais incentivos fiscais e financeiros beneficiam apenas os agraciados por tais medidas, uma vez que diminui o montante do imposto a pagar, tornando patente o aumento de lucro destas empresas e favorecimento indevido de determinados empreendimentos. Sendo assim, ferem o princípio da livre concorrência e causam desequilíbrios sociais, além de descumprir os valores de busca da redução de desigualdades regionais e de bem estar da coletividade (MELO, 2004, p. 274-279).

Após interação sobre a vasta gama de divergências a respeito do assunto, tem-se algumas soluções apontadas pela doutrina e legislação, sem prejuízo da concepção do STF.

\section{Posição do Supremo Tribunal Federal}

Sempre que instado a apreciar a aplicação de normas estaduais que prevejam, unilateralmente, redução de alíquota ou de base de cálculo, crédito presumido, prorrogação de prazo de recolhimento do ICMS e qualquer outra forma de benefício fiscal, o STF as tem suspendido. ${ }^{5}$

João da Silva Medeiros Netto (2003, p. 3), consultor legislativo para assuntos relativos a Direito Tributário da Câmara dos Deputados, chega mesmo a afirmar: "deve ser

5 Neste sentido, entre outros: Marco Aurelio Greco e Anna Paola Zonari de Lorenzo (2001, p. 604); João da Silva Medeiros Netto (2003, p. 3-4) e Ivan Luiz da Silva (julh./ago. 2003, pp. 229-230). 
ressaltado que jamais se viu o Pretório Excelso negar apoio a Estado que denuncia a concessão unilateral de benefício fiscal" ${ }^{6}$

Cotejando-se a jurisprudência do Pretório Excelso, infere-se ser a mesma firme e pacífica no sentido ${ }^{7}$ de:

a) interpretar as normas constitucionais impositivas de disciplina nacional ao ICMS como preceitos contra os quais não se pode opor a autonomia dos Estados - por serem justamente explícitas limitações dela;

b) a exemplo da inteligência dispensada às isenções concedidas à revelia do ordenamento jurídico pátrio, exigir convênio interestadual para aquiescer a concessão por lei estadual de crédito presumido e, quando assim não for, tirar-Ihe a eficácia;

c) havendo periculum in mora, é cabível a concessão em caráter liminar da suspensão do ato normativo estadual que provoque prejuízos à economia e às finanças dos demais Estados.

É certo, deste modo, que o STF tem cumprido seu dever constitucional de preservar o equilíbrio federativo. Todavia, deve-se atentar para a constatação de que o controle repressivo por ele exercido não tem sido suficiente para preservar o equilíbrio federativo. Assim é porque os atos de guerra fiscal tornaram-se regra, quando deveriam ser, no máximo, exceção. ${ }^{8}$

\section{A necessidade da reforma e seus contornos na legislação e na doutrina}

6 Exemplos disso são, também, as seguintes decisões:

a) ADIn n. 1.467, impetrada pelo Governador do Distrito Federal contra a Câmara Legislativa do Distrito Federal (Informativo STF n. 54);

b) ADIn n. 1.999, impetrada pelo Rio Grande do Sul contra legislação de São Paulo (Informativo STF n. 155);

c) ADIn n. 2.157, impetrada por São Paulo contra legislação Bahia (Informativo STF n. 213);

d) ADIn n. 3.246-1, impetrada pelo Procurador-Geral da República contra o Governador e a Assembléia Legislativa do Estado do Pará (DJ de 01.09.2006).

7 Ademais das já referidas, cite-se, exemplificativamente, o estudo de Ivan Luiz da Silva (julh./ago. 2003, p. 229-230) e a Medida Cautelar em ADIn n. 2.772-2-MG, DJU 1-E de 7.11.2003, p. 81 (apud MELO, 2004, p. 281-282).

8 Data venia, equivoca-se Netto (2003, p. 5), que, ao analisar a jurisprudência do STF, entendeu haver "lei para resolver a questão; não há é vontade política ou empenho profissional para procurar resolver a questão por intermédio do Poder Judiciário". É fato que existe uma tolerância, negligência, da parte de muitos Governadores e, até, da Procuradoria da República em relação à guerra fiscal. Mas não se há negar que se o caminho sugerido para solucionar tal conflito for abarrotar o Supremo com infinitas ações tendentes a abolir as concessões unilaterais de benefícios fiscais, há pela frente anos de dispêndio inócuo de dinheiro público. O correto, isto sim, é o controle preventivo. E este só será possível com nova legislação. 
Forçoso notar que a razão de ser do ambiente de beligerância fiscal sufragado pelos Estados-membros reside, em verdade, no vácuo político-jurídico perpetrado de maneira orquestrada e irresponsável por muitos dos Governadores estaduais. A esse respeito, consoante Ives Gandra Martins (apud COSTA, 2002, p. 95):

\begin{abstract}
Nada obstante as mútuas acusações que os Estados se fazem sobre a concessão de estímulos através do ICMS, a Lei Complementar n. 87/96, que terminaria com a guerra fiscal, teve todos os dispositivos dedicados a equacionar o problema, a pedido dos próprios Governadores, vetados pelo presidente da República. Mais do que isso, condicionaram, os Estados, por seus representantes no Congresso, a aprovação do compromisso assumido pelo presidente de vetar os dispositivos que terminariam com a guerra fiscal.
\end{abstract}

Tendo a Lei Complementar n. 87/96 - posteriormente alterada pelas leis complementares n. 114/2002 e 115/2002, dentre outras -, se omitido em disciplinar as isenções, incentivos e benefícios fiscais a serem concedidos e revogados mediante a deliberação dos Estados e do Distrito Federal (art. 155, § 2ํ, XII, g, da Constituição), continua vigente a Lei Complementar n. 24/75, a qual, embora recepcionada pela Constituição Federal de 1988, é produto da centralização administrativa peculiar à época da Ditadura Militar ${ }^{9}$ e que, por isso, não se revela capaz de solucionar a guerra fiscal que tem lugar nos atuais tempos democráticos.

É de evidência palmar, destarte, a premência da edição de uma nova lei complementar que, assentada sobre bases democráticas, determine normas e sanções aptas a efetivamente conciliar a Federação Brasileira, orientando-a no sentido da harmonia, do desenvolvimento econômico, da redução das desigualdades regionais, de toda a principiologia informadora da Constituição de 1988, enfim - direção, esta, impetuosamente sonegada pela guerra fiscal em curso.

\title{
6.1 Soluções debatidas em sede legislativa
}

Note-se que o debate em torno da guerra fiscal e suas possíveis saídas, tanto em nível doutrinário quanto legislativo, não é recente.

9 Com efeito, anota Gustavo F. Cavalcanti Costa (jan.-fev. 2002, p. 95-96), o ranço autoritário da aludida Lei Complementar n. 24/75 manifesta-se com especial ênfase quando delega a ratificação dos convênios aos decretos do Executivo e não às Assembléias Legislativas Estaduais, conforme já tratado. 
Ainda em 2003, movido pelas discussões acerca da "reforma tributária" que então se tratava, e calcando-se nas soluções apresentadas para reduzir, a um mínimo tolerável, a concessão dos benefícios fiscais que, em sede de ICMS, alimentam a guerra fiscal, João da Silva Medeiros Netto (jun. 2003, pp. 6-7) arrolou alternativas para suprimir esse grave problema, a saber:

a) o Senado Federal valer-se de sua competência para fixar alíquotas em operações interestaduais (art. 155, § 2으, IV, da Constituição) ${ }^{10}$, reduzi-las a zero, eliminando, na prática, a tributação de operações interestaduais. Referido autor alerta, porém, que, uma vez adotada, essa solução faria aumentar a sonegação (v.g. Zona Franca de Manaus);

b) cobrar o imposto na origem e repassar o dinheiro arrecadado para o Estado destinatário, o que exigiria uma câmara de compensação interestadual de difícil operacionalização. Os Estados superavitários repassariam recursos aos deficitários;

c) transferir para a União a competência legislativa, salientando-se que o produto da arrecadação seguiria com os Estados. Esta solução constou de forma mitigada no texto da PEC n. 41, de 2003, posto que se permitiria aos Estados indicarem os produtos e serviços tributados, tomando por base os percentuais de alíquota fixados pelo Senado Federal. Outrossim, aludida PEC chegou a prever a proibição da concessão de benefícios fiscais, conquanto tenha delegado a lei complementar fixar penalidades, o que, de fato, já existia e revelava-se inócuo.

A par do exposto, também em 2003, quando se discutia os termos de aludida reforma, aventou-se:

a) unificação da legislação do ICMS, cujas alíquotas ${ }^{11}$ em número de cinco, seriam fixadas por lei complementar, além de, nas operações interestaduais, a receita obtida com o ICMS continuar sendo compartilhada por mais três anos;

b) já a partir de 2007, a parcela da receita cabível ao Estado de origem seria progressivamente reduzida, transferindo-a ao Estado destinatário;

10 Kiyoshi Harada (2006, p. 430) aduz, ainda, que o dispositivo em tela "objetiva mitigar o princípio da tributação na origem com o fito de favorecer os Estados consumidores".

11 A máxima não poderia ultrapassar $25 \%$ e a mínima seria a da cesta básica e de alguns medicamentos, sendo que, por três anos, cada Estado ainda poderia manter quatro produtos com alíquotas superiores em $3 \%$ ao padrão nacional. 
c) além da já mencionada proibição da concessão de novos incentivos fiscais, também se almejava a extinção dos vigentes àquela época em onze anos, exceto os casos da Zona Franca de Manaus e os previstos na Lei de Informática; e,

d) finalmente, a extinção, em 2007, do ICMS, do IPI e do ISS, os quais seriam reunidos no Imposto sobre Valor Agregado, o IVA, com objetivo de simplificar o sistema tributário nacional.

A fim de persuadir os Governadores dos Estados das regiões norte, nordeste e centro-oeste - os maiores responsáveis pela guerra fiscal - a abrirem mão dessa danosa prática, o governo federal propôs a criação de um Fundo de Desenvolvimento Regional, composto por $2 \%$ da arrecadação do IPI e do Imposto de Renda - totalizando aproximadamente $\mathrm{R} \$ 2,1$ bilhões anuais -, a ser repassado aos Estados das mencionadas regiões, além do Rio de Janeiro e Minas Gerais, que têm áreas de baixo desenvolvimento.

No entanto, os dados do CONFAZ ${ }^{12}$ dão conta de que o valor repassado pela União por meio do Fundo em questão, como contrapartida à anuência dos Estados, é quatro vezes menor do que os ganhos de receita obtidos com a guerra fiscal - R\$ 9 bilhões anuais. Daí a resistência dos Governadores (GOBETTI, Unidades..., 6 nov. 2006, Caderno A, p. 6).

Ao cabo das querelas suscitadas, veio a lume a EC n. 42/2003, a qual, no tocante à guerra fiscal em sede de ICMS, diante de incontornável impasse, limitou-se a prever alíquotas mínimas a serem fixadas pelo Senado Federal (art. 155, § 60 , I, da Constituição da República).

Também de se mencionar o Projeto de Lei Complementar n. 373/2006, em tramitação na Câmara dos Deputados, e o Projeto de Lei do Senado n. 240/2006, na Câmara Alta, ambos pretendendo alterar a redação do $\S 2$ 20 da Lei Complementar n. 24/75 e, no último, o $\S 2$ 을 do art. 4으, da mesma lei. Quer-se suprimir o requisito de unanimidade dos votos nas deliberações do CONFAZ para conceder e revogar os benefícios fiscais - pois, na realidade, praticamente se inviabiliza a costura de convênios, ferindo a autonomia dos Estados -, propondo-se que a concordância de 4/5 dos presentes se baste.

Embora constituam tais projetos de lei inegável avanço, não se lhes há de refutar um caráter meramente tópico, não objetivando efetivamente promover o deslinde da guerra fiscal.

12 Cf. nota explicativa n. 1. 


\subsection{Soluções debatidas em sede doutrinária}

A respeito dos pontos suscitados, consoante abalizadas opiniões de Kiyoshi Harada (2006, p. 141-145) e de Dejalma de Campos (2004, p. 347-348), a unificação da legislação do ICMS seria positiva, capaz de trazer benefícios a todos, desde que não se tribute no destino, ${ }^{13}$ uma "retórica vazia e inconseqüente", segundo aquele autor.

No sentir de Campos (2004, p. 347), a transferência do recolhimento para a venda final geraria perda para as áreas mais industrializadas, razão pela qual a cobrança do ICMS (ou IVA) no "destino, é uma proposta inaceitável, a menos que haja uma compensação garantida".

Para acabar com os incentivos tributários no ICMS, afirma Harada, não seria preciso reforma, mas tão-só deixar de concedê-los contra a disposição do art. 151, I, da Constituição, aplicável, também, nas esferas regional e local.

Ainda sob a óptica do citado autor, tendo-se em conta que a desoneração de um sujeito implica necessariamente na oneração de outro, bem como que, onde todos pagam, todos pagam pouco, os incentivos em tela "atentam contra os princípios da isonomia, da transparência e da justiça fiscal que, por sua vez, exige respeito ao princípio da capacidade contributiva" (HARADA, 2006, p. 145), de maneira que devem eles ser "outorgados única e exclusivamente para promover o equilíbrio do desenvolvimento socioeconômico entre as diferentes regiões do país, e não para aprofundar o abismo de uma região da outra, como vem acontecendo" (HARADA, 2006, p. 145).

Por derradeiro, a guisa de proposta para solver a guerra fiscal no tocante ao ICMS, Kiyoshi Harada (2006, p. 146) entende caber aos Estados o imposto sobre o consumo, representado pelo Imposto sobre Valor Agregado (IVA), conservando a tributação na origem; ao passo que ao Senado Federal compete estabelecer alíquotas interestaduais para correção de desigualdades regionais.

Relativamente à proposta de se transferir a competência tributária relativa ao ISS, que seria incorporado ao IVA, dos Municípios para os Estados, como maneira de amenizar as perdas emergentes da reforma, não obstante conveniente para os governadores dos

13 A maior parte dos Governadores deseja a substituição do ICMS pelo IVA, que seria cobrado no destino, segundo informa Dejalma de Campos (2004, p. 347-348), para quem a transferência do recolhimento para a venda final geraria perda para as áreas mais industrializadas, razão pela qual a cobrança do ICMS (ou IVA) no "destino, é uma proposta inaceitável, a menos que haja uma compensação garantida". 
Estados, afirma Campos (jan./fev. 2004, p. 348), trata-se de hipótese tétrica para os Municípios, de maneira que não resolve o problema.

\section{Conclusão}

Muito embora haja inúmeras propostas para solucionar as controvérsias acerca da guerra fiscal em sede de ICMS, seja convertendo-o em legítimo imposto sobre o consumo o qual favoreceria os contribuintes de fato, os quais, em verdade, arcam com a carga tributária do imposto -, seja com alíquotas uniformizadas, criação de lei complementar a dispor sobre a instrumentalização e os mecanismos de concessão da isenção e demais benefícios fiscais, dentre outras sugestões, observa-se que o problema é menos de cerne jurídico do que político, uma vez que, sob a perspectiva do interesse público secundário, mostra-se extremamente interessante para os Governadores dos Estados continuarem com sua política de agraciar certos grupos com incentivos e benefícios fiscais, favorecendo exclusivamente interesses regionais, em prejuízo dos nacionais.

Fica patente a necessidade de uma concertação em prol de uma agenda comum aos Entes Federados, com o desiderato de desenvolver uma normatização nacional que disponha sobre o assunto e trazendo mecanismos lindeiros à concessão do instituto jurídico da isenção e seus congêneres, de forma a respeitar o princípio federativo, sem prejuízo de valores igualmente relevantes, como a busca da igualdade regional e social.

$\mathrm{Na}$ esteira das últimas eleições, presentes à mesa os interesses da União, dos Estados e do Distrito Federal e devendo o Congresso Nacional funcionar em 2007, de se reconhecer não haver melhor momento para se estabelecer a concertação em tela. Não há tempo a perder.

\section{Referências}

CAMPOS, Dejalma de. Os rumos da reforma tributária. Revista Tributária e de Finanças Públicas, São Paulo, v. 12, n. 54, p. 347-350, jan./fev. 2004.

CARRAZZA, Roque Antonio. ICMS. 9. ed. rev. e ampl. São Paulo: Malheiros, 2003. 
COSTA, Gustavo de Freitas Cavalcanti. O conflito de competência exonerativa em matéria de ICMS: uma abordagem político jurídica sobre a "guerra fiscal" na Federação Brasileira.

Revista Tributária e de Finanças Públicas, São Paulo, v. 10, n. 42, p. 85-100, jan./fev. 2002.

GOBETTI, Sérgio. Estado quer revisão tributária ampla. O Estado de São Paulo, São Paulo, 6 nov. 2006. Caderno A, p. 6.

.Unidades menores elevam arrecadação de ICMS e defendem guerra fiscal. O Estado de São Paulo, São Paulo, 6 nov. 2006. Caderno A, p. 6.

GRECO, Marco Aurelio; LORENZO; Anna Paola Zonari de. ICMS - benefícios fiscais - isenções, convênios, imunidades - produtos semi-elaborados. In: MARTINS, Ives Gandra (Coord.).

Curso de direito tributário. 8. ed. São Paulo: Saraiva, 2001.

HARADA, Kiyoshi. Direito financeiro e tributário. 15. ed. São Paulo: Atlas, 2006.

. Possível reforma tributária. Revista Tributária e de Finanças Públicas, São Paulo, v. 11, n. 51, p. 138-145, jul./ago. 2003.

MELO, José Eduardo Soares de. ICMS: teoria e prática. 7. ed. São Paulo: Dialética, 2004.

NETTO, João da Silva Medeiros. Guerra fiscal entre os Estados. Brasília, 2003. Disponível em: <www2.camara.gov.br/publicacoes/estnottec/tema20/pdf/306768.pdf>. Acesso em: 21 out. 2006.

SILVA, Ivan Luiz da. Da inconstitucionalidade dos decretos concessivos de incentivos fiscais em ICMS. Revista Tributária e de Finanças Públicas, São Paulo, v. 11, n. 51, p.225-232, jul./ago. 2003. 
Revista de DiReito Público, LONDRINA, V. 2, N. 1, P. 89-102, JAN./ABR. 2007. 